\title{
UM OBJETO DE ESTUDO SOBRE ENSINO DE ENFERMAGEM PSIQUIÁTRICA E SAÚDE MENTAL
}

AN OBJECT STUDY ABOUT PSYCHIATRIC NURSING AND MENTAL HEALTH TEACHING.

UN OBJETO DE ESTUDIO SOBRE ENSEÑANZA DE ENFERMERÍA PSIQUIÁTRICA Y SALUD MENTAL

Luciane Prado Kantorski ${ }^{1}$

Graciette Borges da Silva ${ }^{2}$

RESUMO: O artigo aborda a construção de um objeto de estudo sobre o ensino de enfermagem psiquiátrica e saúde mental. Apóia-se no referencial teórićometodológico maxista redimensionando conceitos como o ensino - enquanto prática de reprodução e resistência - ideologia/contra-ideologia, atores/sujeitos sociais, saúde mental e reforma psiquiátrica.

PALAVRAS-CHAVE: Ensino - Enfermagem psiquiátrica - Saúde mental - Reforma psiquiátrica.

ABSTRACT: This article approaches the construction of a study object about the psychiatric nursing teaching and mental health. It is supported on the Marxist theoretical-methodological referential making a re-dimensioning of concepts as teaching - as a reproduction and resistance practice - ideology / counter-ideology, actors / social subjects, mental health and the psychiatric reform.

KEYWORDS: Teaching - Psychiatric nursing - Mental health - Psychiatric reform.

RESUMEN: El artículo trata de la construcción de un objeto de estudio sobre la enseñanza de enfermería psiquiátrica y salud mental. Se apoya en el referencial teórico-metodológica marxista redimensionando conceptos como la enseñanza por ahora práctica de reproducción y resistencia - ideología/contra-ideología. actores/sujetos sociales, salud mental y reforma psiquiátrica.

PALABRAS CLAVE: Enseñanza - Enfermería psiquiátrica - Salud mental - Reforma psiquiátrica.

\footnotetext{
${ }^{1}$ Professora Adjunta da Faculdade de Enfermagem e Obstetricia da Universidade Federal de Pelotas e Doutora em Enfermagem pela Escola de Enfermagem de Ribeirão Preto da Universidade de Săo Paulo.

${ }^{2}$ Professora Associada da Escola de Enfermagem de Ribeirão Preto da Universidade de São Paulo.
}

R. Bras. Enferm. Brasilia, v. 51, n. 3, p. 417-430, jul./set., 1998 
Este artigo consiste na apresentação de um caminho para construção de um objeto de estudo sobre o ensino de enfermagem psiquiátrica e saúde mental, constituindo-se em uma reflexão de caráter epistemológico. Para ir delimitando o objeto de estudo elegeu-se o Rio Grande do Sul, pois este estado traz consigo toda uma história de resistência ao modelo psiquiátrico tradicional que pode ser reportada às experiências de comunidade terapêutica desenvolvidas a partir do final dos anos 60 na Clínica Pinel em Porto Alegre e as influências da psiquiatria preventiva, nos anos 70 , com o trabalho de Busnello em Porto Alegre, junto à Unidade Sanitária em São José do Murialdo, cujas experiências passam a ser tomadas como instrumento de modernização das ações de psiquiatria e saúde mental reconhecidas pela Organização Mundial de Saúde. A história dessa resistência, já em décadas anteriores, conferiu aos sujeitos um processo de organização em torno da reforma psiquiátrica que resultou, por exemplo, no fato de o Rio Grande do Sul ser o primeiro estado brasileiro a ter a lei da reforma psiquiátrica aprovada no âmbito estadual.

No interior do sistema universitário gaúcho, o estudo focalizará os cursos de graduação em enfermagem das quatro universidades públicas aí existentes, que são a Universidade Federal do Rio Grande do Sul (UFRGS), a Universidade Federal de Santa Maria (UFSM), a Universidade Federal de Pelotas (UFPel) e a Fundação Universidade do Rio Grande (FURG).

O recorte temporal estabelecido foi a partir do final da década de 80 e decorre de algumas reflexões teóricas sobre a temática, pois, em um levantamento bibliográfico dessa reforma, ao analisar os resumos dos trabalhos veiculados na Literatura Latino-Americana em Ciências da Saúde (LILACS), nos Anais e Programas dos Congressos Brasileiros de Enfermagem e nos artigos publicados na revista Saúde em Debate, observou-se que a discussão acerca da reforma psiquiátrica, divulgada através de produções cientificas, data de final dos anos 80 .

$\mathrm{Na}$ busca das produções específicas acerca do ensino de enfermagem psiquiátrica e saúde mental, constata-se que sua obrigatoriedade nos cursos de graduação em enfermagem instituiu-se a partir de 1949 e pode-se observar, nos artigos das décadas de 50 e 60, como os de Ungaretti (1956), Fernandes (1959) e Minzoni (1966), uma preocupação em descrever o planejamento e o cotidiano do ensino teórico-prático de enfermagem psiquiátrica.

No decorrer das décadas de 70 e 80 , alguns dos artigos produzidos, como os de Foregatto \& Saeki (1973), denotam uma preocupação em refletir sobre as dificuldades encontradas pelos alunos de graduação em enfermagem ao estagiarem no hospital psiquiátrico tradicional, partindo do relato de como se desenvolve o ensino prático. Outros trabalhos, como os de Arantes (1976), Fraga, Damasceno \& Calixto (1986) e de Stefanelli (1986), marcam as 
discussões presentes nas últimas décadas acerca da comunicação e do relacionamento terapêutico que vem a exercer influência sobre o ensino em enfermagem psiquiátrica.

Considera-se que os trabalhos assinalados oferecem um panorama do que tem sido produzido teoricamente sobre o ensino de enfermagem psiquiátrica e saúde mental podendo orientar a análise proposta.

É neste sentido que a tese defendida consiste em reconhecer a reprodução dos saberes e práticas psiquiátricos dominantes no ensino de enfermagem psiquiátrica e saúde mental, evidenciando que, no interior dessa reprodução, se geram contradiçöes, movimentos e mudanças que possibilitam a emergência da resistência enquanto semente para a construção contra-ideológica, o que pode contribuir para o processo de reforma psiquiátrica. Portanto, reafirma-se como pressupostos básicos os explicitados a seguir.

PRIMEIRO PRESSUPOSTO - O ensino de enfermagem psiquiátrica e saúde mental porta uma contradição intrínseca à sua constituição, que se refere à reprodução de modos de pensar e agir que correspondem à ideologia dominante (a qual contribui para a manutenção da hegemonia dos grupos dominantes), existindo em seu interior um espaço de disputa contra-ideológica em que saberes e práticas antagônicos săo trabalhados, pensados e construídos.

Dando seguimento às delimitações do objeto de estudo, recorreu-se ao levantamento de teses e dissertações, acerca da temática, defendidas nas duas últimas décadas, destacando-se os seguintes trabalhos: Fernandes (1982), Teixeira (1988), Lobato (1989), Silva (1991), Proença (1993), Braga (1993) e Barros (1996).

Fernandes (1982) analisa a evolução do ensino de enfermagem e de enfermagem psiquiátrica, no Brasil, de 1930 a 1980, discutindo as determinações político-sociais que o permeiam. Afirma que o ensino de enfermagem foi institucionalizado, no Brasil, em 1923, sob a influência do sanitarismo. Em 1949, através da Lei $n^{\circ} 775$ e do Decreto $n^{\circ} 27.426$, de agosto de 1949, é determinada a obrigatoriedade do ensino de Enfermagem Psiquiátrica nos cursos de graduação em enfermagem. No entanto, conforme o relatório final do levantamento de recursos e necessidades de enfermagem, no Brasil - 1956/1958, apenas $33 \%$ das escolas ofereciam estágios naquela disciplina e, quando ofereciam, os campos eram muito precários (ASSOCIAÇÃO BRASILEIRA DE ENFERMAGEM, 1980).

A autora analisa os programas de ensino da enfermagem psiquiátrica e observa que, de 1930 a 1964, a ênfase são os aspectos clinicos da doença mental, com terapêuticas biológicas, centradas no hospital. Na segunda metade dos anos 50, observam-se as influências da psicanálise e outras correntes 
psicológicas nos conteúdos teóricos, porém os estágios mantêm-se voltados para os cuidados biológicos, individuais, disciplinares. De 1964 a 1980, de forma incipiente, inserem-se alguns princípios da psiquiatria preventiva, através da unidade de higiene mental, e alguns aspectos da assistência de enfermagem nos transtornos psíquicos e psicofármacos, sendo os estágios concentrados também nos hospitais. A autora evidencia que, a partir do final dos anos 60 , ocorre uma mudança nos programas, pois passa-se a abordar terapia familiar e assistência de enfermagem com base no relacionamento terapêutico e os alunos começam a participar de reuniöes de grupo com pacientes, com o ensino sofrendo influências da psiquiatria social e dos princípios da comunidade terapêutica. Na metade dos anos 70 , as mudanças observadas ficam por conta das influências da psiquiatria preventiva ou comunitária, com integração da saúde mental junto a outras disciplinas, ênfase na prevenção e na intervenção comunitária. No entanto, além de os estágios continuarem concentrados nos hospitais, pois mesmo quando realizados em ambulatórios, eles mantinham as práticas tradicionais: na parte teórica a maior carga horária era destinada às psicopatologias, à respectiva assistência de enfermagem e à psicofarmacologia. A autora reforça que, apesar de as mudanças ocorrerem no discurso, elas convergem para os interesses econômicos vigentes em cada momento histórico.

Considera-se que as reflexões da autora convergem para um dos pressupostos do estudo proposto, já que se entende que os movimentos reformistas não conseguiram romper com a prática manicomial, sendo entretanto incorporados à assistência psiquiátrica e passando a compor o discurso hegemônico desde que não ameacem o já estabelecido. É neste sentido que se percebe que as propostas atuais de reforma psiquiátrica contrapõem-se às anteriores, por questionarem a rede de saberes que dão sustentação ao aparato assistencial, jurídico e cultural que tenta justificar o manicômio e, por conseguinte, a exclusão do louco.

SEGUNDO PRESSUPOSTO - Os saberes e práticas que fundamentam a reforma psiquiátrica diferenciam-se do referencial da psiquiatria tradicional ainda hegemônico e dos saberes e práticas dos movimentos reformistas tais como a psicoterapia institucional, a psiquiatria de setor, a comunidade terapêtica, a psiquiatria preventiva ou comunitária, por gerar propostas de ruptura com a reprodução do modelo manicomial e aglutinar outros sujeitos - enfermeirosdocentes e alunos, entre outros - em torno do desafio da transformação do modelo vigente.

Barros (1996), em sua tese, utiliza-se de entrevistas com docentes da Escola de Enfermagem da Universidade de São Paulo, com base no materialismo histórico, para refletir sobre o fenômeno saúde-doença mental, a assistência de enfermagem e o ensino de enfermagem. Aponta que a visão do processo saúde-doença predominante faz uma distinção entre o normal e o patológico, tendo como referência o idealismo da normalidade, do equilíbrio, 
sendo os desvios considerados patológicos. Ressalta que este entendimento produz uma assistência dicotomizada, pois origina dois modelos de atenção, a saber: a psiquiatria (da doença) e a saúde mental (o preventivismo). A assistência de enfermagem tem como objeto o homem a-histórico, reificado na doença e na exteriorização de seu comportamento, sendo que o instrumento de ensino-aprendizagem da enfermagem psiquiátrica é $o$ relacionamento terapêutico realizado com o paciente internado em hospital psiquiátrico, lugar considerado como pouco terapêutico. Reitera que esse saber produzido no ensino não é praticado no processo assistencial dos enfermeiros que desenvolvem mais atividades de supervisão, controle, tarefas burocráticas.

Deste modo, reafirma-se que a escolha de pensar sobre o ensino de enfermagem psiquiátrica e saúde mental em sua relação com o processo de reforma psiquiátrica consiste na tentativa de estabelecer, a partir das contradições encontradas, um diálogo possível. Salienta-se que a inserção (ou não) desse ensino nas lutas por uma reforma psiquiátrica está relacionada a visões de mundo, interesses, projetos politicos e de vida dos atores e sujeitos sociais, podendo ser observadas em espaços como programas das disciplinas, salas de aula, campos de estágio, assim como pensados por interlocutores como professores e alunos. Considera-se ainda, preliminarmente, que há níveis de inserção diferenciados, podendo essa ocorrer, por exemplo, através da definição de conteúdos programáticos, escolha de campos de estágio, realização de eventos para debater a reforma, engajamento no movimento pela reforma psiquiátrica, entre outros.

TERCEIRO PRESSUPOSTO - A possibilidade de docentes e alunos aproximarem-se das propostas e espaços institucionais, que se propõem a construir cotidianamente um modelo assistencial pautado nos preceitos da reforma psiquiátrica, constitui um caminho de confrontos e de recriação do conhecimento, que poderá contribuir para uma reflexão e para que os atores sociais (professores, alunos e demais trabalhadores de saúde) constituam-se no processo contra-ideológico enquanto sujeitos sociais.

Realizadas as delimitações necessárias à construção do objeto de estudo, explicitou-se o mesmo, assim como os objetivos da pesquisa proposta.

O objeto de estudo são as contradições, movimentos e mudanças que perpassam a relação entre o ensino de graduação em enfermagem psiquiátrica e saúde mental nas universidades públicas do Rio Grande do Sul (RS) e os princípios e propostas de reforma psiquiátrica que, aí, se vem construindo desde a década de 80 .

Nesse sentido, tem-se como objetivos: 
- caracterizar os cursos de graduação em enfermagem das universidades públicas do Rio Grande do Sul, resgatando a especificidade do ensino de enfermagem psiquiátrica e saúde mental;

- investigar como o ensino tem-se configurado nos cursos estudados, considerando as contradições, movimentos e mudanças que o permeiam;

- entender de que modo o ensino pode ou não influenciar na reflexão crítica de professores e alunos acerca da reforma psiquiátrica;

- analisar a relação que tem sido construída a partir dos enfermeirosdocentes e dos alunos dos cursos investigados com a práxis da reforma psiquiátrica.

A fim de apreender o objeto de estudo, propõe-se a utilização do referencial marxista, como possibilidade de direcionar as análises dos diferentes modos como atores/sujeitos sociais colocam-se no interior do processo de ensino e em relação à reforma psiquiátrica.

As concepções que se utiliza dizem respeito ao entendimento que se tem acerca do homem enquanto ser social e suas diversas formas de conformar-se e de resistir ao conjunto de circunstâncias e projetos sociais que the dão elementos para posicionar-se na sociedade que, ao ser produzida por ele, também o produz.

Considera-se que o homem, ao transformar a natureza de acordo com um projeto construído conscientemente, ou seja, o trabalho dotado de finalidade, transforma a si mesmo, relativizando assim a sua soberania sobre a natureza. A relativização da referida soberania decorre de fatores externos aos homens singulares e a seus respectivos interesses. Os fatores externos consistem nas circunstâncias materiais e coletivas, em que há oposição de interesses que determinam o modo como se configura a produção. É pertinente, deste modo, relativizar a autonomia e o poder de transformação dos diferentes sujeitos que, concretamente, mesmo que conscientes da necessidade de transformação, por exemplo, da assistência psiquiátrica, por entendê-la como excludente, mesmo desencadeando processos de mudanças, vão encontrar muitas barreiras impeditivas. As barreiras consistem em mecanismos do sistema vigente que concorrem para manter a hegemonia da classe dominante materializadas em formas específicas como, por exemplo, olhar o louco como improdutivo, logo, configurando-se em mais um grupo social que, dentro do sistema capitalista, vem compor o grupo dos excluídos. Institui-se, assim, uma lógica de sociabilidade perversa que, quando abarca os diferentes, o faz baseada em sua capacidade de consumo e não em mecanismos de solidariedade.

Gramsci (1991b: 10) entende o Estado como hegemonia revestida de coerção, sendo formado por uma sociedade política, a qual corresponde ao 
conjunto de mecanismos através dos quais a classe dominante detém o monopólio legal da repressão e da violência, ou seja, o aparelho coercitivo que possibilita adequar a população a um modo de produção dominante. No caso da assistência psiquiátrica, esses mecanismos seriam os dispositivos legais que permitem a internação compulsória, a negação dos direitos de cidadania do louco e a possibilidade legal de acionar instituições policiais- militares para manter a ordem.

Além da sociedade política, compõe o Estado, na concepção gramsciana, a sociedade civil, que corresponde ao conjunto de organizações responsáveis por elaborar e reproduzir ideologias. Aqui se enquadrariam instituições como a escola, a igreja, os partidos politicos, os movimentos sociais, entre outras. A concepção de Gramsci sobre o Estado é extremamente complexa, a princípio porque as instituições executivas, jurídicas, policiais, entre outras, são produzidas por sujeitos portadores de ideologias, assim como as instituições da sociedade civil. No entanto, não existe homogeneidade nos grupos, podendo em determinados períodos históricos haver rupturas, formação de novas alianças, ou seja, rearticularem-se forças em torno do projeto hegemônico ou mesmo contra-hegemônico. Ao mesmo tempo, a relação entre infra-estrutura entendendo que aqui se encontram os mecanismos de produçäo - e superestrutura - entendendo que aqui se encontram os mecanismos de reprodução - não é mecânica, de modo que se possa dizer que automaticamente a infra-estrutura determina a superestrutura. Gramsci (1991a: 52) afirma haver uma relação dialética entre ambas, o que impulsiona a analisar essa relação refletindo a historicidade em que é pensada, os determinantes, as possibilidades de conformismo e resistência.

Assim näo é possivel pensar o caos da assistência psiquiátrica vigente, remetendo para uma postura pessimista que vê que as formas de assistência se constituíram de modo a responder a necessidades de reprodução do modelo econômico-político vigente, extraindo, desta constatação, uma interpretação deterministica que coloca a morte dos sujeitos, já que qualquer movimento vai esbarrar inevitavelmente no modo de produção vigente. Por outro lado, não se advoga a autonomia total do sujeito que, pela sua consciência e vontade, pode modificar todo o modelo de assistência dominante. Entende-se que, neste campo especifico assim como nos demais espaços sociais, se estabelecem conflitos, coexistem diferentes projetos e interesses que respondem a determinados grupos sociais. Nas lutas pela conservação do modelo de assistência psiquiátrica hegemônico ou sua transformação, muitos sujeitos, interesses e projetos configuram-se, gerando, inclusive, concepçőes diferenciadas de manutenção e reforma.

O ensino de enfermagem psiquiátrica e saúde mental e a instituição escolar têm reproduzido um modelo manicomial dominante que promove a exclusão e a 
segregação da loucura, prática que se materializa nos mecanismos de controle e repressão utilizados na atenção psiquiátrica cotidiana, na legislação vigente, em seus preceitos e mecanismos de interdição e internação compulsória, no reforço à dicotomia entre o normal e o patológico. No entanto, no interior desse processo em que as velhas crenças do saber psiquiátrico convivem com as novas crenças de reforma psiquiátrica, as pessoas reproduzem e produzem modos de pensar e agir e constituem-se como sujeitos concorrendo para a conformação e/ou ruptura.

Resgata-se o mérito dos trabalhos que têm mostrado como a prática - seja no ensino ou na assistência - tem reproduzido um corpo de conceitos, valores, relações dominantes no modo de produção capitalista e o trabalho proposto em vários momentos deverá cumprir esta função. Entende-se, no entanto, que os mecanismos de resistência que emergem no processo de reprodução merecem ser olhados com mais atenção porque se configuram em possibilidades reais de aglutinação de outros sujeitos em torno da proposta da reforma psiquiátrica.

Gramsci (1991a: 63) aponta que na sociedade convivem várias concepções de mundo entre as quais o individuo faz uma opções, sendo que o senso comum compartilhado pela maioria dos indivíduos já abriga em seu interior os indícios de uma nova concepção de mundo. Dai a importância da compreensão gramsciana da ideologia enquanto terreno onde os homens se movimentam, adquirem consciência e lutam. O autor reconhece a existência de uma relação orgânica entre conhecimento e práxis, entendendo que a ideologia tem um caráter de unidade em que a força social adquire organicidade e pode levar à hegemonia.

Nesse sentido, a categoria analitica do estudo proposto consiste na ideologia/contra-ideologia entendendo-se que ambas constituem uma totalidade, contrapondo-se sem se excluírem, coexistindo como faces de uma mesma relação em que a manutenção e as rupturas compõem os movimentos, mudanças e contradições da realidade. A ideologia dominante promove a exclusão social do louco, institucionalizando saberes e práticas que dão organicidade à sua exclusão mas, ao mesmo tempo, na reprodução ideológica, emergem possibilidades de contraposição e resistência que se manifestam muitas vezes veladamente na realidade e nas ações dos sujeitos, anunciando espaços de promoção de modos de pensar e agir emancipatórios.

Para entender melhor a questão, é importante, ainda que brevemente, trazer a concepção marxista restrita de ideologia. Marx \& Engels (1989) vão compreender a ideologia enquanto falsa consciência, ilusăo, visão invertida do real, concepção distorcida de idéias em que estas aparecem como motor da vida real, assinalando que a ideologia dominante produz uma consciência deformada da realidade que toma a parte pelo todo. 
Conforme Chauí (1991), para apreender as concepções de Marx e Engels de alienação e ideologia é preciso entender que, quando a classe se autonomiza em relação ao individuo e aparece de maneira invertida como que determinando a posição do desenvolvimento pessoal deste indivíduo, o mesmo fica subsumido a ela. A autora afirma que a ideologia: "... não é um processo subjetivo consciente, mas um fenômeno objetivo e subjetivo involuntário produzido pelas condições objetivas da existência social dos indivíduos" (p. 78).

Para ela, a ideologia é produzida em três momentos fundamentais: inicia como um conjunto sistemático de idéias de pensadores da classe em ascensão produzindo uma universalidade legitimadora da classe; prossegue fazendo com que as idéias e valores da classe emergente sejam aceitas e interiorizadas pela consciência dos não dominantes; mantém-se mesmo quando a classe emergente torna-se dominante, porque a ideologia separa os indivíduos dominantes das idéias dominantes, como se fossem independentes, permitindo a universalização das idéias. Acrescenta que a ideologia como um conjunto de idéias e valores - representações - e de condutas - normas e regras - indica como os indivíduos devem pensar, sentir, o que fazer, o que valorizar, apagando as diferenças de classe e criando um sentimento de identidade social entre os membros da sociedade. Assim, a transformação das idéias não depende delas mesmas, nem das forças que lhes são internas, mas, das transformações nas relações sociais.

Tendo como referência o suporte teórico exposto, este estudo irá se ocupar de apreender expressões da ideologia dominante e da contra-ideologia, manifestas pelos atores e sujeitos do ensino de enfermagem psiquiátrica e saúde mental - professores e alunos. Considera-se que, através dos programas das disciplinas, das falas dos entrevistados e demais instrumentos utilizados na pesquisa, se apresentam modos particulares de reforço ao modelo psiquiátrico manicomial dominante e/ou de reinvenção de novos modos de perceber e lidar com a loucura.

Salienta-se que a ideologia dominante não é mecanicamente incorporada, mas sim reelaborada pelos sujeitos em um movimento de conformismo e resistência ${ }^{3}$, reconhecendo sua dimensão contraditória e seu caráter prático.

Neste momento torna-se fundamental esclarecer como define-se o sujeito social no interior do trabalho proposto. Sader (1988), ao discutir as novas configurações assumidas pelos trabalhadores e movimentos sociais da Grande

\footnotetext{
${ }^{3}$ CHAUI (1986) aborda o conformismo e a resistência a partir de um estudo da cultura popular em uma sociedade com traços autoritários, como a brasileira, afirmando que a cultura popular se efetua dentro da cultura dominante, podendo resistir a ela. Remarca que na cultura popular observam-se aspectos de resistência que podem ser difusos - como 0 humor anônimo, os ditos populares - ou localizados em açōes coletivas. A autora não se refere a açōes deliberadas de resistência, mas a algumas práticas que, sendo dotadas de certa lógica, se configuram em formas de resistência.
} 
São Paulo, na década de 70 , apresenta uma definição de sujeito social, a qual adotou-se. $\mathrm{Na}$ sua pesquisa, associa a noção de sujeito à existência de um projeto e à idéia de autonomia. Afirma que um traço comum no emprego do conceito de sujeito encontrado no interior dos novos movimentos sociais é:

... o fato de a noção de sujeito vir associada a um projeto, a partir de uma realidade cujos contornos não estão plenamente dados e em cujo devir o próprio analista projeta suas perspectivas e faz suas apostas. E outro traço comum, vinculado a este, é a conotação com a idéia de autonomia, como elaboração da própria identidade e de projetos coletivos de mudança social a partir das próprias experiências (Sader, 1988: 53).

Deste modo, entende-se que a denominação ator social designa individualidades que compõem o senso comum e sujeito social designa atores emergentes que se aglutinam em torno de um projeto social e político que visa a transformar a ordem hegemônica, contrapor-se e resistir a ela.

Outro aspecto importante na definição de Sader (1988) consiste no resgate da autonomia do sujeito. Castoriadis (1991) desenvolve o seu entendimento de autonomia contraposto à alienação a partir da máxima da psicanálise proposta por Freud, a saber: "Onde era o Id será o Ego"e acrescenta que, se para Lacan, "o inconsciente é o discurso do Outro", a autonomia seria o âmbito em que o meu discurso passa a ser a instância de decisão, tomando o lugar de um discurso estranho a mim que me domina. O sujeito autônomo, para o autor, não é nem um sujeito enquanto atividade-pura, ou seja, como compreendem muitos filósofos subjetivistas, livre de determinações externas, mas é aquele capaz de reelaborar o discurso do Outro em função de suas vontades. O sujeito autônomo é também atividade, intencionalidade, é também o corpo no mundo, antes de qualquer pensamento que possa ser refletido. A concepção apresentada pelo autor sugere que a autonomia está no centro dos objetivos do projeto de transformação e, portanto, tem de ser pensada para todos os homens, sua concretização requerendo um trabalho coletivo.

$\mathrm{Na}$ perspectiva do resgate do sujeito social, aglutinado em torno de um projeto com vistas à construção de autonomia, utiliza-se o conceito de saúde mental adotado por Fagundes (1992), no qual essa autora reitera que a saúde é determinada socialmente e que o ser torna-se humano ao participar da cultura, estruturando assim sua identidade, subjetividade e singularidades. Deste modo, a saúde mental consiste em um estado de equilibrio relativo entre os elementos conflitivos que constituem a pessoa, os grupos e a cultura. Este conceito articula a existência de crises previsíveis e imprevisiveis e a participação ativa da pessoa em suas mudanças e nas do contexto social.

Compreendende-se a saúde mental dessa forma, considera-se o movimento de reforma psiquiátrica como estratégia de resistência que visa viabilizar novos modos de pensar e agir em relação à loucura. Resistência esta que se configura na contraposição hegemônica a um modo tradicional de assistência que se tem 
mostrado muito funcional e coerente com os interesses da sociedade capitalista. A partir desse entendimento, toma-se a reforma psiquiátrica como potencialmente transformadora de relações, sujeitos, modos de pensar e fazer que dizem respeito à relação da sociedade com as pessoas portadoras de sofrimento psíquico.

Deste modo, compartilha-se, com Amarante (1994: 43), da afirmação de que a reforma psiquiátrica:

... não mais se refere exclusivamente à reformulação dos serviços, ao rearranjo do aparato assistencial-normativo, nem reestruturação do texto jurídico que trata da matéria; não significa ainda a descoberta de novas técnicas, de uma escuta ou de uma terapêutica perfeitamente qualificada e competente, de por assim dizer, definitiva. Reforma psiquiátrica no nosso entendimento, é o conjunto de iniciativas políticas, sociais, culturais, administrativas e jurídicas que visam transformar a relação da sociedade para com o doente. A reforma psiquiátrica que estamos construindo vai das transformações na instituição e no poder médico psiquiátrico até as práticas em lidar com as pessoas portadoras de problemas mentais.

A fundamentação exposta até aqui contribui para a explicitação da opção da dialética como método de investigação, já enunciada pela escolha de autores marxistas. Konder (1981), ao estudar o caráter materialista da dialética, a partir de Engels e Marx, ressalta algumas de suas características e princípios. $O$ autor aponta que, para a dialética, os fenômenos da natureza não podem ser compreendidos isoladamente, incorrendo-se no risco de, ao isolar os fenômenos, convertê-los em algo sem sentido. Na dialética, os fenômenos são compreendidos como um todo, ligados organicamente aos que o cercam, condicionando-se reciprocamente. A natureza e a sociedade é olhada como um estado de movimento, transformação, renovação e desenvolvimento incessantes. Por isto, a interpretação dialética exige que os fenômenos sejam compreendidos além de suas relações e condicionamentos recíprocos, sob a perspectiva do movimento, da transformação. O processo de desenvolvimento é considerado não como simples crescimento, mas como um processo que passa de mudanças quantitativas e latentes às mudanças qualitativas radicais e bruscas que se verificam em saltos. Segundo a compreensão dialética, os fenômenos encerram uma contradição interna, expressada em seu lado positivo e negativo, no velho e no novo, entre o que se desagrega e se desenvolve. $O$ autor ressalta que, mesmo evidenciando principios e caracteristicas da dialética, a mesma não pode ser aprisionada em codificações.

$\mathrm{Na}$ apreensão do objeto de estudo - o ensino de enfermagem psiquiátrica e saúde mental em sua relação com a reforma psiquiátrica, dentro de uma perspectiva dialética, é necessário recuperar historicamente a constituição do ensino que a realidade apresenta, considerando os movimentos, mudanças, 
conflitos e contradiçōes que o compōem assim como as suas relações com a psiquiatria e com as transformações mais gerais da sociedade. Essa apreensão irá utilizar-se de fontes como documentos e falas de professores e alunos, enquanto grupo social que constitui o todo concreto dessa prática, e os dados construidos a partir dai configuram as análises elaboradas. Propōe-se uma tentativa de superar a aparência da realidade, direcionando a análise para o entendimento das relações, condicionamentos, determinações, assim como movimentos, mudanças e possibilidades de transformação do aparentemente dado, constituido, conformado. Deste modo, a problemática a ser estudada visa apreender os mecanismos de reprodução da ideologia dominante - o corpo de conceitos e práticas psiquiátricas hegemônicas reproduzidas no ensino - e os mecanismos de resistência e contraposição - configurados nos princípios e propostas de reforma psiquiátrica.

\section{REFERÊNCIAS BIBLIOGRÁFICAS}

1. AMARANTE, P.. Algumas reflexões sobre ética, cidadania e desinstitucionalização na reforma psiquiátrica. Saúde Debate, n. 45, p. 43-46, dez. 1994.

2. ARANTES, E. C.. O ensino de relacionamento terapêutico em enfermagem psiquiátrica. R. Bras. Enferm., v. 26, n. 6, p. 439-446, 1973.

3. ASSOCIAÇÃO BRASILEIRA DE ENFERMAGEM. Relatório final do levantamento de recursos e necessidades de enfermagem no Brasil 1956/1958. Brasilia, 1980.

4. BARROS, S.. O Louco, a loucura e a alienaçāo institucional: o ensino de enfermagem psiquiátrica sub judice. São Paulo, 1996. 202p. Tese (Doutorado) - Escola de Enfermagem, Universidade de São Paulo.

5. BRAGA, V. A. B.. A enfermagem e a disciplina enfermagem psiquiátrica: visão da aluna. Ribeirão Preto, 1993. 138 p. Dissertação (Mestrado) - Escola de Enfermagem de Ribeirão Preto, Universidade de São Paulo.

6. CASTORIADIS, C.. A instituição imaginária da sociedade. Trad. de Guy Reynaud. 3. ed. Rio de Janeiro: Paz e Terra, 1991.

7. CHAUI, M.. Conformismo e resistência: aspectos da cultura popular no Brasil. São Paulo: Brasiliense, 1986.

8. O que é ideologia. 34. ed. São Paulo: Brasiliense, 1991. (Coleção Primeiros Passos, n. 13). 
9. FAGUNDES, S.. Saúde mental coletiva: a construção no Rio Grande do Sul. In: BEZERRA JÚNIOR, B.; AMARANTE, P. (orgs.). Psiquiatria sem hospício: contribuições para o estudo da reforma psiquiátrica. Rio de Janeiro: Relume Dumará, 1992. p. 57-68.

10. FERNANDES, D. A. B.. Plano de ensino em enfermagem psiquiátrica. $R$. Bras. Enferm., v. 12, n. 4, p. 380-403, 1959.

11. FERNANDES J. D.. O ensino de enfermagem e de enfermagem psiquiátrica no Brasil. Salvador, 1982. 111 p. Dissertação (Mestrado) - Universidade Federal da Bahia.

12 FOREGATTO, A.R.F.; SAEKI, T.. Dificuldades encontradas pelos alunos de enfermagem ao estagiar num hospital psiquiátrico tradicional. $R$. Enferm. Esc. Enfermagem. Ribeirão Preto, v. 1, n. 2, p. 56-62, 1973.

13. FRAGA, M. N. O..; DAMASCENO, R. N.; CALIXTO, M.L.G. Ensino de relacionamento terapêutico em enfermagem psiquiátrica: dificuldades e perspectivas. R. Bras. Enferm., v. 39, n. 2/3, p. 94-102, abr./set. 1986.

14. GRAMSCI, A.. A concepção dialética da história. Trad. de Carlos Nelson Coutinho. 9. ed. Rio de Janeiro: Civilização Brasileira, 1991a.

15. Os intelectuais e a organização da cultura. Trad. de Carlos Nelson Coutinho. 8. ed. Rio de Janeiro: Civilização Brasileira, 1991 b.

16. KONDER, L.. O que é dialética. São Paulo: Brasiliense, 1981. (Coleção Primeiros Passos, n.23).

17. LOBATO, R. C.. Influência da disciplina enfermagem psiquiátrica na formaçāo do enfermeiro. Ribeirão Preto, 1989. 88p. Dissertação (Mestrado) - Escola de Enfermagem de Ribeirão Preto, Universidade de São Paulo.

18. MARX, K.; ENGELS, F.. A ideologia alemã. Trad. de Luis Claudio de Castro e Costa. São Paulo: Martins Fontes, 1989.

19. MINZONI, M. A.. Levantamento do ensino da enfermagem psiquiátrica nas escolas de enfermagem do Brasil. R. Bras. Enferm., v. 9, n. 5/6, p. 558568, out./dez. 1966.

20. PROENÇA, J. F.. Compartilhando reflexöes sobre o ensino de enfermagem psiquiátrica na Escola de Enfermagem da Universidade Federal Fluminense. Niterói, 1993. 52p. Dissertação (Mestrado) - Escola de Enfermagem, Universidade Federal Fluminense.

21. SADER, Eder.. Quando novos personagens entram em cena: experiências e lutas dos trabalhadores da Grande São Paulo 1970-1980. Rio de Janeiro: Paz e Terra, 1988. 
22. SILVA, M.C.P.. Análise do ensino da disciplina enfermagem psiquiátrica nos cursos de graduaçāo em enfermagem da Grande São Paulo. São Paulo, 1991. 129p. Dissertação (Mestrado) - Escola de Enfermagem, Universidade de São Paulo.

23. STEFANELLI, M. C.. Ensino de técnica de comunicação terapêutica enfermeira-paciente parte I. R. ESC. Enferm. USP, São Paulo, v. 20, n. 2 , p. 161-183, ago. 1986.

24. TEIXEIRA, M.B.. Percepçāo e sentimento das alunas durante 0 periodo em que estavam cursando a disciplina de enfermagem psiquiátrica do curso de graduação em enfermagem. São Paulo, 1988. 221p. Tese (Doutorado) - Instituto de Psicologia, Universidade de São Paulo.

25. UNGARETTI, N. M.. Orientação da cadeira de enfermagem psiquiátrica da Escola de Enfermagem de Porto Alegre. R. Bras. Enferm., v. 9, n. 4, p. 285-294, 1956. 